\title{
EDUCAÇÃO DO CAMPO NOS ÚLTIMOS 20 ANOS: CONQUISTAS, RETROCESSOS E RESISTÊNCIAS
}

\author{
Lucinete Gadelha da Costa
}

Professora da Universidade Federal do Estado do Amazonas - UEA, vinculada ao Programa de Pós-graduação em Educação em Ensino de Ciências na Amazônia. Líder do grupo de estudo e pesquisa em Formação de Professores para a Educação em Ciências na Amazônia (GEPEC/UEA)

\section{Ana Cláudia da Silva Rodrigues}

Professora do Departamento de Fundamentação da Educação, Centro de Educação, vinculada ao Programa de Pós-graduação em Educação, Universidade Federal da Paraíba. Doutora em Educação pela Universidade Federal da Paraíba. Líder do grupo de Pesquisa Currículo Práticas Educativas.

Orcid: https://orcid.org/0000-0001-6621-1861

Lucielio Marinho da Costa

- Professor do Departamento de Fundamentação da Educação. Doutor em Educação pela Universidade Federal da Paraíba. Integrante do Grupo de Estudos Educação Popular e Movimentos Sociais do Campo - PPGE/UFPB; Currículo e Práticas Educativas - UFPB. ORCID: https://orcid.org/0000-0002-5872-4349

\begin{abstract}
RESUMO
A luta dos últimos 20 anos por uma educação destinada aos povos do campo no Brasil constitui o objeto de estudo deste artigo. As questões de pesquisa foram: Quais políticas públicas se estabeleceram no Brasil para a educação do campo? Como os movimentos sociais populares do campo contribuíram para a instituição do debate sobre a escola do campo? Que avanços, retrocessos e resistências para a consecução de uma educação democrática se instauraram? $\mathrm{O}$ objetivo consistiu em analisar como os movimentos sociais populares do campo impulsionaram as discussões de políticas públicas destinadas às escolas do campo, no referido período. Os procedimentos metodológicos foram organizados a partir da abordagem qualitativa, o tipo de estudo é bibliográfico e documental. Os achados da pesquisa foram analisados numa perspectiva dialética. As reflexões resultantes indicam a construção de ações em prol da educação do campo na agenda governamental no período de 1998 a 2016, com conquistas legais significativas, resultantes de embates entre os movimentos sociais e o governo federal. Após afastamento da presidente da República, Dilma Rousseff, 2016 a 2018, estabelece-se um período de latência que propicia a nova estrutura da educação no Brasil, efetivada através do Decreto $n^{\circ}$ 9.665, de 02 de janeiro de 2019, que excluiu a Secretaria da Educação do Campo da estrutura governamental, denotando a necessidade de novos estudos para verificação das consequências desta ação.
\end{abstract}

Palavras-chave: Educação do campo. Políticas públicas. Educação democrática.

\section{EDUCATION OF THE FIELD IN THE LAST 20 YEARS: ACHIEVEMENTS, SETBACKS AND RESISTANCE}

\begin{abstract}
The struggle of the last 20 years for an education aimed at rural peoples in Brazil constitutes the study object of this article. The research questions were: what public policies were established in Brazil for rural education? How did the peasant social movements contribute to the institution of the debate on the peasant school? What advances, setbacks and resistances for the achievement of a democratic education have been established? The objective was to analyze how peasant social movements stimulated discussions of public policies aimed at the rural schools in the period. The methodological procedures were organized from the qualitative approach, the type of study is bibliographic and documentary. The research findings were analyzed in a dialectical perspective. The resulting reflections indicate the construction of actions for the education of the field in the governmental agenda from 1998 to 2016, with significant legal achievements resulting from clashes between the social movements and the federal government. After the removal of the president, Dilma Rousseff, 2016 to 2018, a latency period is established that provides the new
\end{abstract}


structure of education in Brazil, implemented through Decree n. 9,665 of January 2, 2019, which excluded the Secretariat of Field Education from the governmental structure, denoting the need for further studies to verify the consequences of this action.

Keywords: Education of the field. Public policy. Democratic education.

\section{EDUCACIÓN DEL CAMPO EN LOS ÚLTIMOS 20 AÑOS: CONQUISTAS, RETROCESOS Y RESISTENCIAS}

\section{RESUMEN}

La lucha de los últimos 20 años por una educación destinada a los pueblos del campo en Brasil constituye el objeto de estudio de este artículo. Las cuestiones de investigación fueron: ¿qué políticas públicas se establecieron en Brasil para la educación del campo? ¿Cómo los movimientos sociales populares del campo contribuyeron a la institución del debate sobre la escuela del campo? ¿Qué avances, retrocesos y resistencias para la consecución de una educación democrática se instauraron? El objetivo consistió en analizar cómo los movimientos sociales populares del campo impulsaron las discusiones de políticas públicas destinadas a las escuelas del campo, en el referido período. Los procedimientos metodológicos se organizaron a partir del enfoque cualitativo, el tipo de estudio es bibliográfico y documental. Los hallazgos de la investigación fueron analizados en una perspectiva dialéctica. Las reflexiones resultantes indican la construcción de acciones en pro de la educación del campo en la agenda gubernamental en el período de 1998 a 2016, con logros legales significativos, resultantes de embates entre los movimientos sociales y el Gobierno Federal. Después de la expulsión de la presidenta de la República, Dilma Rousseff, 2016 a 2018, se establece un período de latencia que propicia la nueva estructura de la educación en Brasil, efectuada a través del Decreto $n^{\circ}$ 9.665, de 02 de enero de 2019, que excluyó a la Secretaría de Educación del Campo de la estructura gubernamental, denotando la necesidad de nuevos estudios para verificar las consecuencias de esta acción.

Palabras clave: Educación del campo. Políticas públicas. Educación democrática.

\section{INTRODUÇÃO}

Pensar a organização da educação não hegemônica, considerando a ação democrática participativa, alicerçada na atuação de movimentos e organizações sociais populares, para uma parcela da população que reside na zona rural do Brasil, durante um período de 20 anos, constituiu-se no objeto de estudo deste texto.

As motivações de pesquisa surgiram a partir das tentativas de invisibilidade, descaracterização e ocultação da atuação de movimentos e organizações sociais na formulação e implementação de políticas públicas para a educação do campo, por grupos políticos que ascenderam ao poder nas últimas eleições no Brasil. As questões que direcionaram a pesquisa foram: Quais políticas públicas se estabeleceram no Brasil para a educação do campo? Como os movimentos sociais populares do campo contribuíram para a instituição do debate sobre a escola campesina? Que avanços, retrocessos e resistências para a consecução de uma educação democrática participativa se instauraram? 
O objetivo consistiu em analisar como os movimentos sociais populares do campo impulsionaram as discussões de políticas públicas, destinadas às escolas do campo. O foco foram os programas institucionais do governo federal, implementados e executados em parceria com instituições públicas, cujas ações foram voltadas para ofertar cursos de educação básica (alfabetização, ensinos fundamental e médio), técnicos profissionalizantes de nível médio, cursos superiores e de pós-graduação (especialização e mestrado, para jovens e adultos de assentamentos de todas as regiões do país.

O aporte teórico utilizado para discutir os achados da pesquisa foram Santos, B. (2003, 2005), que estuda a categoria Democracia Participativa; Caldart (2000a, 2004a, 2005), que apresenta os princípios constitutivos dos projetos de educação para as escolas do campo; Arroyo (2012), que trata dos novos sujeitos que vivem no espaço geográfico campesino e suas novas identidades e Ball e Bowe (1992) e Ball (1994), que propuseram a análise de políticas a partir do que denominou de Ciclo Contínuo de Políticas - que é composto por cinco contextos: Influência, Produção de Texto, Prática, Efeitos/Resultados e Estratégia Política. Neste texto abordaremos, principalmente, o contexto de influência que nos ajuda a refletir sobre as incursões dos movimentos sociais populares do campo na produção de políticas para a educação nesses espaços.

Não se compreende políticas educacionais distantes das pessoas que as atuam, através de um processo de interpretação e tradução para colocá-las em ação, uma vez que estas políticas são resultado de processos históricos de constituição de sujeitos, responsáveis por sua criação em momentos históricos distintos, que serão posteriormente "recriadas" em outros espaços, por outros sujeitos, em outras realidades.

Existe uma necessidade de analisar políticas educacionais "considerando que estas se encontram permeadas por discursos oficiais e não oficiais, advindos daqueles que vivenciam as políticas, mas que nem sempre conseguem ter voz". As disputas e interesses entre os formuladores da política são postos no "Contexto da Produção de Texto", por representar também o momento em que essas políticas são formuladas. De acordo com Mainardes (2007, p. 105), “é importante salientar nesta análise que ‘texto’ nem sempre se refere a um documento escrito, mas ao formato que a política foi tomando no decorrer do tempo".

Em muitos escritos sobre política educacional, frequentemente não se dá valor ao significado de política e/ou é definida superficialmente como em uma tentativa de "resolver um problema". Geralmente, essa resolução de problema é feita por meio da 
produção de textos de políticas como legislações ou outras prescrições e inserções voltadas local ou nacionalmente à prática (BALL, 1992, p. 13).

Por isso, o "ciclo de políticas" preenche o espaço que existia ao se tentar analisar políticas como algo estático, visto que oferece uma estrutura conceitual para compreendermos que percursos foram construídos durante o processo de formulação, as compreensões e novos significados de sua implantação, os efeitos e as consequências para os sujeitos envolvidos na política, ou seja, não ignoram as disputas e os embates durante o processo de elaboração e atuação da política.

Enfatiza-se que o "Contexto de Influência", indicado por Ball (1992), independe das formas de governo instituídas nos países e para a formulação de políticas. Mainardes (2007, p. 27) expõe a "natureza complexa e controversa da política educacional, enfatizam os processos micropolíticos e a ação dos profissionais que lidam com as políticas em nível local", indicando "a necessidade de se articularem os processos macro e micro na análise de políticas educacionais".

Neste aspecto compreende-se a política enquanto uma trajetória em relação ao contexto histórico, social e cultural. Não se reduz a algo estático, mas que tem caráter dinâmico, movimenta-se, interpreta, reinventa, interfere, infere, produz ações, sujeitos, atos, identidades. Agir na produção de políticas é dar sentido, ter sentido, criar sentidos. Por isso, a importância de se compreender que sujeitos/atores/organizações/movimentos contribuíram para a produção de políticas e programas para a educação do campo em um contexto considerado democrático participativo.

Para Santos, B. (2003, p. 50), as concepções alternativas não-hegemônicas de democracia surgiram após a segunda metade do século $\mathrm{XX}$ e buscaram entender a "democracia como forma de aperfeiçoamento da convivência humana". Para o autor, discutir este conceito de democracia consiste em compreendê-la como "forma sóciohistórica" que não é determinada por quaisquer tipos de leis naturais.

Santos, B. (2003) destaca ainda que práticas democráticas participativas ampliam o horizonte para experiências de emancipação social, visto que proporcionam que grupos sociais tomem parte e colaborem com a produção de políticas e programas que respondam às demandas de parcelas da população que estão à margem da sociedade ou são segregadas localmente.

Nosso interesse residiu nas conexões entre os movimentos e organizações sociais e a elaboração de políticas e programas educacionais, a partir da atuação de sujeitos que 
compreendiam o processo democrático e disputavam o significado da democracia como práticas políticas de reconhecimento da diferença, especialmente no início do século XXI, quando o Brasil passou a ser governado por Luiz Inácio Lula da Silva (2003-2006; 20072010) e Dilma Rousseff (2011-2014; 1015-abril de 2016¹), ambos do Partido dos Trabalhadores (PT).

Esse processo de disputa que se instaurou no país, entre os grupos e movimentos sociais organizados e o Estado resultou em uma inclusão de políticas e programas para atender a uma parcela da população que teve, até aquele período, seus direitos sociais e políticos negados. Neste texto discutiremos a compreensão de democracia participativa (SANTOS, B., 2003) e, através das seções sobre "As políticas e programas para educação do campo nos últimos 20 anos", "Movimentos Sociais: tecendo leituras sobre sua atuação" e "Retrocessos e Resistências: novos espaços de aprendizagens" como direcionadoras das respostas às questões problemas formuladas.

\section{MOVIMENTOS SOCIAIS: TECENDO LEITURAS SOBRE A ATUAÇÃO DOS MOVIMENTOS POPULARES DO CAMPO NO DIRECIONAMENTO DE POLÍTICAS PÚBLICAS}

Apesar da forte influência do Estado e sua aparente finalidade de manutenção da marginalização da educação rural ao longo do processo de escolarização no Brasil, constatam-se ao longo da história movimentos contra-hegemônicos que foram responsáveis por organizar as demandas dessa população e reivindicar uma educação contextualizada que observasse os contextos locais e valorizassem a cultura campesina.

Faz-se necessário enfatizar que os movimentos sociais populares denunciaram e continuam denunciando o caráter excludente da educação e, por meio de processos de resistência, lutam pelo resgate de um espaço escolar que, de fato, seja emancipador.

Para que se construa esta possibilidade é necessário que se realize uma prática voltada para os interesses das camadas populares, uma vez que não devemos conceber a escola fora do contexto social e histórico. A escola pode se constituir em instrumento de

\footnotetext{
${ }^{1}$ No dia 17 de abril de 2016 o Parlamento brasileiro aprovou, por 367 votos favoráveis e 137 contra, a instalação de um processo de impeachment da presidenta Dilma Rousseff, do Partido dos Trabalhadores (PT), eleita por mais 54 milhões de votos, dando posse a Michel Temer, então Vice-Presidente, para governar o país. Fonte: https://pt.wikipedia.org/wiki/Lista_de_presidentes_do_Brasil.
} 
dominação, como também, em espaço de luta por meio dos sujeitos que dela fazem parte, assumindo-se como espaço a serviço dos interesses dos trabalhadores.

É nesse sentido que movimentos sociais de reivindicação de uma educação popular do campo vão se constituindo, em um cenário paradoxal de educação rural, que oferece uma educação de caráter assistencialista, enquanto pretende despolitizar os povos do campo a partir de uma perspectiva de manutenção dos interesses dominantes.

Os movimentos sociais populares caracterizam-se como espaço coletivo, em que se organizam para reivindicar e efetivar seus interesses e analisar que enquanto espaços de socialização política, os movimentos permitem aos trabalhadores o aprendizado prático de como unir, organizar, negociar e lutar e partem em direção à formação da identidade social.

Os movimentos sociais de caráter popular, cuja prática, segundo Calado (2007, p. 99) vislumbra o "[...] compromisso com a construção de uma sociabilidade alternativa ao modelo capitalista de organização social". De modo geral, esses movimentos sociais têm em comum a luta por mudanças sociais que decorrem das contradições que se evidenciam na sociedade em seus aspectos econômicos, políticos e culturais.

Segundo Ribeiro (2010, p. 29), são “[...] os movimentos sociais populares, os portadores do novo, do projeto popular de sociedade e de educação [...]”. Nesse sentido, novas condições de dignidade e de justiça social, de transformação da ordem vigente, de respeito à dignidade humana dos desiguais são postas como legítimas nos processos reivindicatórios que precisam ser renovados e reorganizados, em diferentes contextos históricos.

Nesta perspectiva, diversos são os movimentos sociais que se empenharam e se empenham na busca da valorização das culturas diferenciadas (negros, indígenas, ribeirinhos, pescadores, agricultores etc.), dentre eles se destaca o Movimento dos Trabalhadores Rurais Sem Terra, que luta há bastante tempo por direito à terra e a uma educação que atenda a diferentes realidades dos povos do campo, das florestas e das águas.

No Brasil há uma diversidade cultural com cidades e comunidades em contextos rurais, cada localidade possui costumes e cultura diferente e enfrentam dificuldades peculiares, como por exemplo, a enchente dos rios, vazantes, verão severo etc. Também podemos citar o calendário específico de cada localidade (época da colheita, produção, pescas, crença etc.). Ao pensarmos em diferentes realidades vem à tona a necessidade de 
uma educação contextualizada como parte das necessidades específicas dos povos dos diferentes campos.

Neste contexto os movimentos sociais populares do campo se originam dos conflitos em torno da luta por terra, mas também se rebelam contra as relações sociais de produção marcadas pela exploração, pela dominação e degradação da pessoa humana, como a escravidão, contra a negação da cidadania, pelos direitos sociais e trabalhistas, pelo reconhecimento das diferentes culturas e avançam na luta em prol de políticas públicas e de ações afirmativas que atendem aos interesses da classe trabalhadora.

Os movimentos sociais populares do campo têm como foco principal de reivindicação pela Reforma Agrária, entendida como uma das bases para a construção de um novo projeto de sociedade que questiona o latifúndio brasileiro e busca melhores condições de vida para os camponeses.

Os movimentos em prol da educação sempre estiveram trilhando caminhos com algumas divergências referentes ao movimento pela transformação social, ou seja, formar cidadão do campo, tentando mostrar sua realidade sociocultural. São lutas pelo acesso à terra e por uma educação de que pudessem desfrutar, ao longo desse processo, conquistas no campo das políticas públicas.

Mais do que uma realidade diferente do modo de vida urbana, o campo é um espaço de existência social de vida que expressa todas as realizações materiais e não materiais da totalidade social. Verifica-se que as pessoas do campo não eram valorizadas e sempre foram considerados sem cultura, sem educação e, pior do que isso, era como se servissem, apenas, para o trabalho no campo. Tais condições históricas colaboraram para emergir a luta pela terra no interior do movimento, bem como sua luta pelo acesso à educação pública que, para os movimentos sociais populares do campo representa um movimento em prol da educação do/no campo das águas e das florestas.

Na década de 1990, destaca-se um esforço político organizativo, numa conjugação de forças de diferentes movimentos sociais do campo que começaram a construir o Movimento por uma Educação de Campo, por entender que o modelo de educação e a escola rural não contribuíam com o projeto de campo que os camponeses pretendiam.

O Movimento por uma Educação do Campo defende um projeto de educação fundamentado na tradição da Educação Popular e como um conjunto estruturado de princípios, conceitos e práticas, trazendo um sentido claro de crítica ao sistema capitalista 
que controla os meios de produção e captura as sociabilidades que sustentam as comunidades tradicionais (ESMERALDO; MOLINA; ANTUNES-ROCHA, 2017).

Esse movimento tem como marcos de referência o I Encontro Nacional das Educadoras e Educadores da Reforma Agrária (I ENERA), realizado no ano de 1997, na cidade de Brasília/Distrito Federal e a I Conferência Nacional Por uma Educação Básica do Campo, realizada no ano de 1998, na cidade de Luziânia, no estado de Goiás, ambos protagonizados pelos movimentos sociais do campo.

A Educação do Campo considera os modos de produção da vida, a cultura, as características, as necessidades dos que vivem no campo. Portanto, é impossível pensar na Educação do Campo sem referi-la aos sujeitos concretos, históricos, à infância, à adolescência, à juventude, aos adultos que vivem e se constituem enquanto humanos, na luta para garantir a vida, através do acesso à terra.

Pode-se dizer que a luta pela educação do campo não é uma questão local ou regional, ela é abrangente. Quando falamos em Educação do campo, estamos falando de uma educação que foi forjada nas lutas dos movimentos sociais populares por políticas públicas, na luta por direitos para que possam ter condições de vida digna em seus territórios com moradia digna, educação, segurança, saúde, trabalho entre outros. Segundo Souza (2006) a educação do campo é um território de conhecimento que está sendo construído para que se possa compreender o mundo desde suas raízes.

A Educação do Campo é uma construção de um novo conceito de educação, relaciona o conhecimento, a cultura e os saberes com uma linguagem contextualizada, formando sujeitos críticos e transformadores de sua realidade. Fernandes e Molina (2004) afirmam que a Educação do Campo pensa o campo e sua gente, seu modo de vida, que trazem suas particularidades na organização do trabalho em suas diversas atividades econômicas; no espaço geográfico que revela a identidade territorial na organização política e de suas identidades culturais, bem como os seus conflitos trazidos nas lutas de resistências e de afirmação de diversidades.

A Educação do Campo busca valorizar o direito e a identidade do homem do campo, pois o povo tem direito de ser educado no lugar onde vive, o povo tem direito a uma educação pensada vinculada à sua cultura e às suas necessidades humanas e sociais.

\section{AS POLÍTICAS E PROGRAMAS PARA EDUCAÇÃO DO CAMPO}


Nesta seção apresentaremos as políticas e programas iniciados durante o período do governo conhecido como de esquerda no Brasil. Esse processo político para Ball e Bowe (1992) faz parte de um ciclo constituído pelo que denominam de arenas políticas: a política proposta, a política de fato e a política de uso. Para os autores a "política proposta" se refere à política oficial relacionada às intenções do governo, de políticos responsáveis pela elaboração da política, de estudiosos e pesquisadores que influenciam com seus estudos os discursos produzidos, as escolas e autoridades locais de onde a política emerge. A "política de fato" se caracteriza pelos textos políticos que darão forma e serão responsáveis por colocar na prática a política. E a "política em uso" se refere aos discursos e às práticas que se originam quando os profissionais que atuam no nível da prática começam a lidar com os textos políticos.

Ball e Bowe (1992) não compreendem este processo como estático, pois se interrelacionam e não são lineares. Os contextos apresentam arenas, embates e têm grupos de interesses, por isso se denominam de arenas de disputas, pois através de disputas, embates e conflitos direcionarão a formação da política e consequente produção do texto político. Para Mainardes (2007),

É nesse contexto que grupos de interesse disputam para influenciar a definição das finalidades sociais da educação e do que significa ser educado. Atuam nesse contexto as redes sociais dentro e em torno de partidos políticos, do governo e do processo legislativo. É também nesse contexto que os conceitos adquirem legitimidade e formam um discurso de base para a política. O discurso em formação algumas vezes recebe apoio e outras vezes é desafiado por princípios e argumentos mais amplos que estão exercendo influência nas arenas públicas de ação, particularmente pelos meios de comunicação social. Além disso, há um conjunto de arenas públicas mais formais, tais como comissões e grupos representativos, que podem ser lugares de articulação de influência.

É justamente nesse momento, de construção dos textos políticos, que abordaremos a influência dos movimentos sociais populares do campo nas políticas criadas para a população do campo. A arena política nesse período foi caracterizada, principalmente, pela disputa de dois modelos de educação: um com perspectivas neoliberais voltadas para o agronegócio e o outro o modelo agroecológico de respeito à diversidade e à formação humana. Registramos que não aprofundaremos as disputas desta arena que reverberaram em políticas curriculares de caráter avaliativo. Mas, destacaremos como foi possível 
incluir, na produção dos textos políticos, princípios norteadores defendidos pelos movimentos sociais populares do campo.

Inicialmente esclarecemos que a Educação do Campo traz à tona a necessidade de uma educação que supere a dicotomia entre rural e urbano. No entanto, fica evidente a histórica ausência de políticas públicas que considerem, na sua formulação e atuação, as diferenças entre campo e cidade, no sentido de que a vida em ambos os meios se tece de maneira distinta e que políticas "universalistas", baseadas em um parâmetro único (e geralmente urbanizado), que não se aproxima das necessidades, potenciais saberes e desejos dos que vivem no campo, acabam por reproduzir a desigualdade e a exclusão social, distanciando cada vez mais os sujeitos do campo do exercício de sua cidadania. Uma educação que afirme relações de pertença ao mesmo tempo diferenciadas e abertas para o mundo. “[...] pertencer significa se reconhecer como integrante de uma comunidade e um sentimento que move os sujeitos a defender as suas ideias, recriar formas de convivência e transmitir valores de geração a geração" (BRASIL, 2002, p. 36).

Essas características são contempladas nas Diretrizes Operacionais para a Educação Básica nas Escolas do Campo (BRASIL, 2002), que norteia o funcionamento das escolas nesse contexto, trazendo uma nova forma de pensar a escola do campo como construtora de um projeto político e pedagógico na relação com um projeto de desenvolvimento para o país.

A proposta da escola no campo está atrelada à concepção camponesa em relação à terra, ao trabalho e à cultura com respeito aos seus tempos diferenciados diretamente ligados a valores de vida, memória, cultura de um povo. As suas inquietações e conflitos emergem num processo dinâmico, de recriação, fazem parte de um contexto que engloba a sociedade, sua organização, sua estrutura, sua cultura e história. Desse modo, a educação está ligada a esse contexto e ao mundo de cultura que orienta um modelo homem/mulher que se pretende formar para responder aos desafios da sociedade.

Essa questão é retomada por Arroyo (2004) quando reflete acerca das práticas educativas na relação do particular com o universal, destacando que defender o específico do campo não significa desarticulá-lo do geral. Enquanto sujeitos, somos únicos, e a formação da classe trabalhadora do campo tem suas especificidades.

Nesse sentido, os movimentos sociais do campo não negam o construído no campo educacional, eles o reconstroem em uma diferente concepção, gerando uma nova perspectiva educacional, que vai muito além do aspecto de caráter pedagógico e não separa 
os três elementos fundamentais que são: campo, concepção de educação e políticas públicas.

Para Arroyo (2004, p. 97), “ o reconhecimento dessa nova dinâmica humana que se revela no campo poderá ser o alicerce de nossas políticas educativas”. É preciso trazer para a escola a concreticidade das condições específicas do universo rural, da vida camponesa, entendendo esse conhecimento, valorizando o homem do campo e sua cultura, pois esta precisa ser estudada e contextualizada. Entendemos que o desafio da educação do campo é o de contribuir para a formação de sujeitos comprometidos com práticas sociais éticas, possibilitando o estabelecimento de novas formas de relações que se baseiem em valores humanos tais como a solidariedade, o respeito mútuo e a honestidade.

Na década de 90, a luta por uma Educação no e do Campo foi travada pelos educadores ligados aos movimentos sociais populares do campo que, num processo de resistência, construíram experiências, assumindo um compromisso na definição de uma política de Educação Popular do e no Campo. Dessa forma, o Movimento Por uma Educação no e do Campo passou a configurar a constituição de uma proposta educacional voltada aos sujeitos do campo, na defesa de seus interesses, na luta pela terra e pelo trabalho. Nesse sentido, Caldart (2008, p. 73) salienta:

\begin{abstract}
O que nos parece fundamental entender para não nos desviarmos das discussões de origem é que a especificidade de que trata a Educação do Campo é do campo, dos seus sujeitos e dos processos formadores em que estão socialmente envolvidos. Não tem sentido, dentro da concepção social emancipatória que defendemos afirmar a especificidade da Educação do Campo pela educação em si mesma; menos ainda pela escola em si mesma (uma escola específica ou própria para o campo). Isso é reducionismo. Politicamente perigoso e pedagogicamente desastroso.
\end{abstract}

Retomamos na construção de uma política para as Escolas do Campo a I Conferência Nacional por uma Educação do Campo, realizada em 1998, em que foram discutidos e elaborados os princípios pedagógicos da Educação do Campo, que são: o papel da escola enquanto formadora de sujeitos, articulada a um projeto de emancipação humana; a valorização dos diferentes saberes no processo educativo, os espaços e tempos de formação dos sujeitos da aprendizagem; o respeito à temporalidade do homem do campo; o lugar da escola vinculado à realidade dos sujeitos; e por fim, a Educação do Campo como estratégia para o desenvolvimento do país (BRASIL, 2004b). 
O Princípio Pedagógico do papel da escola enquanto formadora de sujeitos articulada a um projeto de emancipação humana é fundamentado na concepção de uma educação que respeita a cultura e a história de vida de cada camponês, perpassando a construção de um currículo contextualizado, o que, para Freire (2002, p. 51), constitui-se:

A partir das relações do homem com a realidade, resultante de estar com ela e de estar nela, pelos atos de criação, recriação e decisão, o homem vai dinamizando o seu mundo. Vai dominando a realidade. Vai humanizando-a. Vai acrescentando a ela algo de que ele mesmo é o fazedor. Vai temporizando os espaços geográficos. Faz cultura.

Os saberes construídos a partir da interação entre seres humanos e natureza, em seus cotidianos na busca de soluções para seus próprios problemas e desafios, também são conteúdos socialmente válidos, significando que o currículo, conforme Moreira (2001, p. $5)$,

[...] é visto como território em que ocorrem disputas culturais, em que se travam lutas entre diferentes significados do indivíduo, do mundo e da sociedade, no processo de formação de identidades. Essa constatação levanta, inevitavelmente, algumas questões. Que identidades os atuais currículos estão ajudando a produzir? Que identidades deveriam produzir? Identidades em sintonia com padrões dominantes ou identidades plurais? Identidades comprometidas com o arranjo social existente ou identidades questionadoras e críticas?

Os movimentos sociais populares do campo, diante desses questionamentos, têm, através de suas experiências, destacado a valorização dos diferentes saberes no processo educativo, salientando que o trabalho pedagógico na "escola precisa levar em conta os conhecimentos que os pais, os/as alunos/as, as comunidades possuem, e resgatá-los dentro da sala de aula num diálogo permanente com os saberes produzidos nas diferentes áreas de conhecimento" (BRASIL, 2004b, p. 37).

Esses elementos estão destacados na Lei de Diretrizes e Bases da Educação (9.394/96), em seu artigo $28^{\circ}$, quando se refere à escola rural, dizendo que os "sistemas de ensino promoverão as adaptações necessárias à sua adequação às peculiaridades da vida rural e de cada região" (BRASIL, 1996). Essa legislação regulamenta o ensino escolar do campo, ampliando seu sentido de abrangência, considerando que a educação está relacionada ao mundo do trabalho. 
Art. 28 - Na oferta da educação básica para a população rural, os sistemas de ensino promoverão as adaptações necessárias à sua adequação, às peculiaridades da vida rural e de cada região, especialmente: I - conteúdos curriculares e metodologias apropriadas às reais necessidades e interesses dos alunos da zona rural; II - organização escolar própria, incluindo adequação do calendário escolar às fases do ciclo agrícola e às condições climáticas; III - adequação à natureza do trabalho na zona rural.

Defende-se a afirmação de uma identidade própria para o meio rural, que fortaleça novas formas de relações sociais e produtivas no campo, baseadas na justiça social, na cooperação agrícola, no respeito ao meio ambiente e na valorização da cultura camponesa. Isso pode ser percebido no artigo $2^{\circ}$, parágrafo único da referida legislação (BRASIL, 2002).

A identidade da escola do campo é definida pela sua vinculação às questões inerentes à sua realidade, ancorando-se na temporalidade e saberes próprios dos estudantes, na memória coletiva que sinaliza futuros, na rede de ciência e tecnologia disponível na sociedade e nos movimentos sociais em defesa de projetos que associem as soluções exigidas por essas questões à qualidade social da vida coletiva no país.

$\mathrm{O}$ entendimento da escola vinculada à realidade dos sujeitos é reforçado pelo artigo $6^{\circ}$ das Diretrizes Operacionais para as Escolas do Campo, que determinam o regime de colaboração entre os entes federados na oferta de educação às pessoas do campo. Essa é uma expressão da luta pela afirmação da identidade camponesa no respeito à diversidade, que caracteriza a população que vive no campo, como salienta Freire (1987, p. 32):

Tem que ser forjada com ele e não para ele, enquanto homens ou povos, na luta incessante da recuperação de sua humanidade. Pedagogia que faça da opressão e de suas causas objeto de reflexão dos oprimidos, de que resultará o seu engajamento necessário na luta por uma libertação, em que esta pedagogia se fará e se refará.

O respeito à temporalidade do homem do campo é outro princípio que estabelece uma relação com as formas de produção, respeitando peculiaridades, características de cada comunidade expressas através da cultura local. Essa atitude de respeito à temporalidade expressa uma visão oposta ao modelo capitalista, que considera a cultura/produção camponesa como atrasada e improdutiva, considerando que seu objetivo é a produção em larga escala, independente das formas desumanas que se possam utilizar para atingir suas finalidades. 
Jesus (2004) destaca que o respeito à produção de conhecimento em diferentes temporalidades e à cultura de cada grupo social, na valorização dos ciclos de vida na terra por meio de conhecimentos e estratégias é um grande desafio da proposta da Educação do Campo.

O Princípio Pedagógico da Educação do Campo como estratégia para a construção de um projeto político de desenvolvimento social para o país se constitui como essência das lutas dos movimentos sociais do campo. Assim, o projeto de Educação do Campo se articula ao projeto popular de desenvolvimento do campo, assumindo uma visão de totalidade, em contraposição à visão reducionista e excludente do campo que ainda predomina em nosso país (CALDART, 2004a).

Mesmo conscientes de que a educação não resolve tudo, os movimentos sociais através da Educação do Campo questionam a forma escolar, buscando uma concepção de escola e de educador articulada com a luta dos trabalhadores. Segundo Freitas (1991), as novas formas escolares não nascerão nas universidades, podem até nascer com a nossa ajuda. Isso por uma razão básica relacionada aos objetivos educacionais que estamos perseguindo.

Na Educação do Campo, a escola é vista como um lugar social de aprendizagem, pois se constitui a partir de seus sujeitos, tornando-se singular e, principalmente, na construção, afirmação e fortalecimento da identidade camponesa. Os trabalhadores atuam com o objetivo de classe na transformação social. Considerando que se aprende na vida, a escola não pode estar isolada, pois é parte do cotidiano real dessa realidade. A escola, nesse processo formativo, precisa estar ao lado de outras agências formadoras, como destaca Freire (2002, p. 67):

Mas, por uma educação que, por ser educação, haveria de ser corajosa, propondo ao povo a reflexão sobre si mesmo, sobre o seu tempo, sobre suas responsabilidades, sobre o seu papel no novo clima cultural da época de transição. Uma educação que lhe propiciasse a reflexão sobre seu próprio poder de refletir e que tivesse sua instrumentalidade, por isso mesmo, no desenvolvimento desse poder, na explicitação de sua potencialidade, de que decorreria sua capacidade de opção.

Formar sujeitos envolvidos nas lutas sociais exige o reconhecimento de que a centralidade da escola precisa ser revista, pois a realidade é permeada de contradições. Precisamos conhecê-las e para isso necessitamos de outro tipo de escola, não a que omite, 
mas a que possibilita o desvelar dessas contradições. O espaço educacional se constitui como um centro de poder e, dependendo dos princípios que orientam seu funcionamento, poderá atuar na linha de manutenção das relações sociais vigentes ou abrir espaços concretos de encaminhamento dos interesses das camadas populares. Assim, a consciência da necessidade da escola, do aprender, da produção de conhecimento está ligada ao direito historicamente negado às camadas populares.

Para Caldart (2000a), ocupar a escola representa dois significados fundamentais, considerando que historicamente, assim como a terra de que foram arrancados, a escola também é um direito negado aos trabalhadores do campo que precisa ser recuperado na construção de uma nova sociedade, cujo modelo de desenvolvimento não pode prescindir da escolarização do povo, especialmente daquele que vive e trabalha no meio rural. Num contexto de construção de uma proposta contra-hegemônica, no embate político ideológico por afirmações de projetos inserem-se as proposições dos movimentos camponeses em defesa da Educação do Campo. Nesse sentido, Molina (2004, p. 19) afirma:

O movimento inicial da Educação do Campo foi o de uma articulação política de organizações e entidades para denunciar a luta por políticas públicas de educação no e do Campo, e para a mobilização popular em torno de outro projeto de desenvolvimento. Ao mesmo tempo tem sido um movimento de reflexão pedagógica das experiências de resistência camponesa, constituindo a expressão, e aos poucos o conceito de educação do campo.

A proposição de uma escola diferente pelos movimentos sociais vai contra a lógica da expropriação dos trabalhadores, apresenta-se na identificação com a terra, com a cultura dos povos do campo, com a valorização da especificidade das relações sociais e produtivas que acontecem nesse espaço. Essa perspectiva na Educação do Campo não pode ser entendida deslocada da concepção da Educação Popular, que traz à tona a luta dos movimentos sociais populares, expressando as reivindicações dos trabalhadores por políticas públicas nas diversas áreas, como a saúde, a educação e o desenvolvimento local.

A partir dos princípios defendidos pelos movimentos sociais populares do campo que seus representantes, em disputa com forças políticas conservadoras que atuavam no Estado e promoveram durante muitos anos um processo de exclusão social, político e econômico da população campesina, neste novo espaço democrático participativo 
conseguiram alicerçar as políticas públicas específicas para a educação do campo considerados por Santos e Silva (2016, p. 3), "como embriões de democratização, socialização de poder, superação de desafios, afirmação de identidades e seres humanos preocupados com o fortalecimento de ambientes coletivos".

Durante o período de atuação dos movimentos sociais populares nas comissões responsáveis por pensar a política para a Educação do Campo, destaca-se a elaboração de documentos que consideravam os princípios dos grupos sociais do campo, tais como o Parecer CNE/CEB N: 36/2001 - Diretrizes Operacionais para a Educação Básica nas Escolas do Campo (BRASIL, 2002); a Resolução CNE/CEB 1, de 3 de abril de 2002, que institui Diretrizes Operacionais para a Educação Básica nas Escolas do Campo (BRASIL, 2002). Referências para uma política nacional de educação do campo. Criação de um grupo de trabalho permanente vinculado ao Ministério da Educação para pensar as políticas de educação para o campo. A partir deste grupo foram organizados os Cadernos de Subsídios (BRASIL, 2004b); o Parecer CNE/CEB Nº 1/2006 que trata de dias letivos para a aplicação da Pedagogia de Alternância nos Centros Familiares de Formação por Alternância (CEFFA) (BRASIL, 2006); o Parecer CNE/CEB N 23/2007 - orientações para o atendimento da Educação do Campo (BRASIL, 2007); a Resolução nº 2, de 28 de abril de 2008 - Estabelece diretrizes complementares, normas e princípios para o desenvolvimento de políticas públicas de atendimento da Educação Básica do Campo (BRASIL, 2008); a Resolução $n^{\circ}$ 5, de 17 de dezembro de 2009 que instituiu as Diretrizes Curriculares Nacionais para a Educação Infantil (BRASIL, 2009); o Decreto no 7.352, de 4/11/2010 - Dispõe sobre a política de Educação do Campo e o Programa Nacional de Educação na Reforma Agrária - PRONERA (BRASIL, 2010a) e a Resolução nº 4, de 13 de julho de 2010 - que estabeleceu as Diretrizes Curriculares Nacionais Gerais para a Educação Básica (BRASIL, 2010b).

Para operacionalizar estas políticas, após várias negociações, foram criados os programas responsáveis por conduzir e atender aos desafios da escolarização dos jovens e adultos das áreas rurais do país. Em ordem crescente apresentamos o Programa Nacional de Educação na Reforma Agrária - PRONERA (1998); Programa Saberes da Terra (2005); Projovem Campo Saberes da Terra (2007); Programa Nacional de Educação do Campo PRONACAMPO (2012); Programa de Apoio às Licenciaturas em Educação do Campo PROCAMPO (2012). 
As lutas dos movimentos sociais do campo pela terra, reforma agrária, vida digna, desdobrando-se em luta territorial, compõem os elementos que fazem parte das reflexões da proposta ideológica e filosófica da Educação do Campo. Nesse movimento de luta, os movimentos sociais incluíram a educação como um dos elementos constitutivos da luta por Reforma Agrária, associando-se ao conjunto de direitos historicamente negados a homens e mulheres do campo; foi assim que se deu o delineamento do PRONERA.

O PRONERA é uma política pública nacional, defendida e construída pelos sujeitos do campo em movimentos que resistiram e persistiram no processo de consolidação e sua institucionalização em 2009, com a Lei no 11.947 (FERNANDES; TARLAU, 2017).

Foi no I Encontro Nacional de Educadores e Educadoras da Reforma Agrária - I ENERA, em julho de 1997, em Brasília, promovido pelo Movimento dos Trabalhadores Rurais Sem Terra (MST) e outros movimentos sociais do campo, que foram dados os primeiros passos para a implementação do PRONERA.

$\mathrm{Na}$ ocasião, um grupo de militantes e de educadores do MST se reuniu com professores universitários presentes no evento, com o objetivo de socializar experiências de universidades brasileiras que estavam desenvolvendo atividades em parceria com os movimentos. Segundo Molina (2003, p. 51), foi nessa ocasião que o MST desafiou os representantes das universidades para que "assumissem a tarefa de construir uma rede nacional entre as universidades, visando enfrentar o problema do analfabetismo nos assentamentos, uma das grandes dificuldades encontradas pelas educadoras e educadores da reforma agrária”.

Sobre a importância do I ENERA como espaço coletivo de discussão e planejamento de um projeto de educação pública para o campo brasileiro, Santos, C. (2009, p. 42) assinala que "[...] o que era para ser um encontro sem grandes pretensões, objetivando a troca de experiências sobre o que vinha se fazendo em matéria de educação nos assentamentos, transformou-se no embrião de uma significativa mobilização nacional pela Educação do Campo". Essa mobilização se materializou no fomento do PRONERA e na organização da I Conferência Nacional de Educação do Campo, realizada em julho de 1998, sendo um marco que originou a concepção de Educação do Campo.

O programa Saberes da Terra foi criado para oferecer qualificação profissional e escolarização para filhos de agricultores familiares, com idade entre 18 e 29 anos, que estavam fora da faixa idade/série para conclusão do ensino fundamental. Os cadernos de formação elaborados para orientação das atividades dos tutores responsáveis pelas aulas do 
programa respeitavam as características, necessidades e pluralidade de gênero, étnicoracial, cultural, geracional, política, econômica, territorial e produtivas dos povos do campo.

O programa teve início em 2005 como mais uma ação da Secretaria Nacional de Juventude, através do Programa Nacional de Inclusão de Jovens (PROJOVEM), que já conduzia as ações das modalidades Adolescente, Trabalhador e Urbano. Segundo dados do portal do programa, na página do Ministério da Educação, os projetos aprovados em parcerias com instituições de Ensino Superior públicas tinham como meta em 2008 atender 35 mil jovens.

O Programa de Apoio à Formação Superior em Licenciatura em Educação do Campo (PROCAMPO) foi instituído em 2009 e pretendeu apoiar a implementação de cursos regulares de licenciatura em educação do campo nas instituições públicas de ensino superior de todo o país, voltados especificamente para a formação de educadores para a docência nos anos finais do ensino fundamental e ensino médio nas escolas rurais.

O PRONACAMPO foi criado com o Decreto $\mathrm{n}^{\mathrm{o}} 7.352$, de 2012, e instituído por meio de Portaria $\mathrm{n}^{\mathrm{o}}$ 86, de 1 de fevereiro de 2013, e tinha como objetivo o apoio financeiro e técnico para auxiliar no desenvolvimento de políticas públicas para o campo. Em seu primeiro artigo o referido decreto institui:

Art. $1^{\underline{0}}$ A política de educação do campo destina-se à ampliação e qualificação da oferta de educação básica e superior às populações do campo, e será desenvolvida pela União em regime de colaboração com os Estados, o Distrito Federal e os Municípios, de acordo com as diretrizes e metas estabelecidas no Plano Nacional de Educação e o disposto neste Decreto.

Para viabilizar a execução desta política o PRONACAMPO se caracterizou como "um conjunto de ações articuladas que assegurem a melhoria do ensino nas redes existentes, bem como a formação dos professores, produção de material didático específico, acesso e recuperação da infraestrutura e qualidade na educação do campo" (BRASIL, 2013, p. 04). Foi estruturado sob quatro eixos que organizavam as ações de I Gestão e Práticas Pedagógicas; II - formação Inicial e Continuada de Professores; III Educação de Jovens de Adultos e Educação Profissional; IV - Infraestrutura Física e Tecnológica. 
O primeiro eixo referente à Gestão e Práticas Pedagógicas foi responsável pela execução do Programa Nacional do Livro Didático (PNLD Campo). Para isto o governo promulgou a Resolução no 40/2011 que designou o Fundo Nacional de Desenvolvimento da Educação (FNDE) e a Secretaria de Educação Continuada, Alfabetização, Diversidade e inclusão (SECADI) para elaboração de editais, avaliação e seleção dos livros. Os textos submetidos ao PNLD Campo compreendiam a alfabetização matemática, letramento e alfabetização, língua portuguesa, matemática, ciências, história e geografia, integradas em coleções multisseriadas ou seriadas, disciplinares, interdisciplinares ou por área do conhecimento (BRASIL, 2013).

O Programa Nacional Biblioteca da Escola - PNBE Temático foi destinado para a atender às bibliotecas das escolas da rede pública de ensino e incluía as temáticas da diversidade, inclusão e cidadania buscando o desenvolvimento de valores, práticas e interações sociais. O Mais Educação Campo teve início em 2013 e tinha como objetivo contribuir para organizar a educação integral nas escolas do campo e de comunidades quilombolas; os recursos específicos eram destinados à ampliação da jornada escolar, integrando atividades de acompanhamento pedagógico e enriquecimento curricular nas diversas áreas do conhecimento.

O segundo eixo destinava-se à Formação Inicial e Continuada de Professores e à organização, acompanhamento e estruturação da Escola da Terra. O terceiro eixo referente à Educação de Jovens e Adultos e Educação Profissional se encarregou dos programas EJA Saberes da Terra e Programa Nacional de Acesso ao Ensino Técnico e Emprego. Tais programas tinham como propósito promover a inclusão social através da Rede Federal de Educação Profissional e Tecnológica através de cursos de formação inicial e continuada de trabalhadores a partir da realidade de cada região.

O quarto eixo que trata da Infraestrutura Física e Tecnológica tinha como área de atuação a construção de escola, inclusão digital, Luz para Todos na Escola, Transporte Escolar, além dos programas PDDE Campo - programa Dinheiro Direto na Escola e PDDE Água e Esgoto Sanitário - Programa Dinheiro Direto na Escola.

Elegemos neste texto o PRONERA para apresentar as principais características, avanços e dificuldades no processo de atuação política do programa para educação na reforma agrária, no estado da Paraíba. Especificamente detalharemos sua origem, parcerias durante a execução das ações e estruturas dos cursos propostos, por entender que por ser este o primeiro programa aprovado, durante o que estamos compreendendo como período 
de democracia participativa, seus resultados contribuem para uma reflexão sobre a atuação desta política no "contexto da prática" (BALL, 1994).

A criação do PRONERA se deu em um cenário marcado por contradições, quais sejam: os objetivos e finalidades do projeto de educação do Estado e do projeto vislumbrado no PRONERA e as políticas públicas planejadas sob a égide dos preceitos do capital globalizado e o projeto político do movimento por Educação do Campo. De acordo com Jezine (2011), além de uma disputa de projetos políticos, sociais, culturais e educacionais, uma disputa no campo ideológico, presente nas formulações políticas e nas práticas sociais e culturais dos sujeitos.

Em todo o território brasileiro, no período 1998 a 2011, segundo dados do relatório da II Pesquisa Nacional sobre a Educação na Reforma Agrária, o PRONERA realizou e concluiu 320 cursos, em nível de Educação de Jovens e Adultos (EJA), Ensino Fundamental, Médio e Superior, envolvendo 82 instituições de ensino, 38 organizações demandantes e 244 parceiros, com a participação de 164.894 educandos (BRASIL, 2015). Essas ações qualificaram a formação educacional e profissional de trabalhadoras e trabalhadores, melhorando suas vidas, reescrevendo seus territórios e mudando o campo brasileiro para melhor, contemplando 880 municípios brasileiros, em todas as unidades da federação.

A maioria dos cursos foi de alfabetização de jovens e adultos, contribuindo para a diminuição do índice de analfabetismo em todo o país. A diversidade de cursos de nível médio foi resultado da procura pela profissionalização para a formação de jovens lideranças para as comunidades, como também profissionais de nível superior de fora do território, mas que passaram a atuar nos assentamentos, com a criativa experiência dos cursos de Residência Agrária (FERNANDES; TARLAU, 2017), destacando-se o acesso ao ensino superior com a criação de 54 cursos no período, quais sejam: pedagogia, história, geografia, sociologia, ciências naturais, agronomia, direito e medicina veterinária, entre outros.

Em 20 anos de história, o PRONERA contribuiu para o fortalecimento da identidade camponesa, através do acesso à educação em todos os níveis, promovendo formação profissional em nível médio e superior, por meio de acordos de cooperação com universidades, em todas as regiões brasileiras, contribuindo com as experiências agroecológicas e com a produção de tecnologias, inovando e criando lideranças de comunidades, cooperativas e associações de produtores (IPEA, 2016). 
No estado da Paraíba, os cursos do PRONERA aconteceram em 64 municípios, beneficiando populações residentes em todas as regiões do estado, desde a Zona da Mata (Litoral) ao Sertão. Vale salientar que muitos cursos tiveram uma abrangência regional ou nacional, recebendo estudantes de vários estados brasileiros, o que ampliou o alcance do PRONERA na Paraíba para além de suas fronteiras (CORREIA, 2013).

Com um total de 21 cursos, a Paraíba se destaca entre os estados da Federação que mais desenvolveram o PRONERA no país, ao lado do Rio Grande do Sul e Bahia com 27 e 23 cursos, respectivamente (BRASIL, 2015). Em parceria com a UFPB, os cursos de formação foram iniciados no ano de 1999, com a realização do Curso de Alfabetização de Jovens e Adultos, no Campus I, na cidade de João Pessoa, envolvendo cerca de 1.200 estudantes camponeses e o Curso de Magistério-Nível Médio [1], no Campus III, na cidade de Bananeiras, envolvendo 32 estudantes.

Em termos de formação de professores em nível superior para jovens e adultos assentados da Reforma Agrária, três áreas foram e/ou estão sendo contempladas: Ciências Agrárias, História e Pedagogia. Em relação a esse nível de formação, o PRONERA tem como principal objetivo proporcionar a formação profissional através de cursos superiores de graduação ou pós-graduação, de modo que os qualifiquem para que estes possam contribuir na promoção do desenvolvimento das áreas de Reforma Agrária. Conforme explicitado no Manual de Operações do PRONERA, “os cursos devem contemplar as situações-problema vivenciadas pelos assentados a fim de que os alunos encontrem soluções para os problemas e, simultaneamente, se capacitem" (BRASIL, 2004a, p. 47).

A seguir apresentaremos algumas considerações sobre os cursos realizados e/ou em execução, no estado da Paraíba. Curso de Licenciatura Plena em Ciências Agrárias. Este foi realizado no período de 2004 a 2008, no Campus III da UFPB, na cidade de Bananeiras/PB, do qual participaram estudantes de assentamentos de diversos estados brasileiros: Paraíba, Pernambuco, Rio Grande do Norte, Piauí, Sergipe, Maranhão, Ceará, Espírito Santo, Mato Grosso do Sul, Tocantins, São Paulo, Paraná e Minas Gerais.

O referido curso foi normatizado pela Resolução do Conselho Superior de Ensino, Pesquisa e Extensão da Universidade Federal da Paraíba, № 41/2003, a qual aprovou o seu Projeto Político-Pedagógico, apresentando como propósito a formação de profissionais da educação, graduados em Ciências Agrárias, com formação técnico-pedagógica e preparo humanístico, político e psicossocial (UFPB, 2003). 
Curso de Licenciatura em História. Este vem sendo realizado pelo Departamento de História do Centro de Ciências Humanas, Letras e Artes (CCHLA/UFPB), Campus I, na cidade de João Pessoa, para educadores dos movimentos sociais do campo, vinculados aos Assentamentos da Reforma Agrária no Brasil e tem sido demandado pelos movimentos vinculados à Via Campesina. Sua criação se deu com a aprovação da Resolução $N^{\circ}$ 17/2004 do CONSEPE/UFPB.

A primeira turma deste curso aconteceu no período de 2004 a 2008, a segunda de 2008 a 2011 e a terceira no ano 2015, com estimativa de finalização neste ano de 2019. Ao finalizar sua terceira turma, segundo dados da coordenação deste curso, tem-se como estimativa a formação de um total de 150 camponeses e camponesas, oriundos de 23 estados brasileiros. De acordo com o Projeto Pedagógico do curso, os egressos poderão desenvolver ações educativas, formadoras, com perspectiva de atender a 05 assentamentos rurais por educando (UFPB, 2004).

\section{Curso de Pedagogia - Licenciatura em Magistério dos Anos Iniciais do Ensino}

Fundamental. A primeira turma desse Curso de Pedagogia foi ofertada no período de 2008 a 2011, no Centro de Educação da UFPB, também na cidade de João Pessoa/PB. Sua segunda turma foi iniciada no ano 2015, com estimativa de conclusão no ano 2018. Ao concluir sua segunda turma, no total, o curso tem como meta formar aproximadamente 70 educadores das áreas de assentamento rural da reforma agrária, de diferentes municípios do estado da Paraíba, Ceará e Pernambuco.

O referido curso foi aprovado pela Resolução No 61/2007 do CONSEPE/UFPB e tem como objetivo proporcionar a formação de professores em nível superior em pedagogia, com aprofundamento na área de Educação de Jovens e Adultos (EJA), para atuar na docência nos níveis Educação Infantil e Anos Iniciais do Ensino Fundamental, bem como em projetos educativos, nas áreas de assentamento.

Conforme consta em seu Projeto Político-Pedagógico, esse curso foi criado por iniciativa da Comissão Pastoral da Terra do Estado da Paraíba (CPT/PB), que teve como finalidade formar, em nível superior, os/as estudantes egressos/as do Curso de Magistério em Nível Médio, anteriormente mencionado (UFPB, 2007).

Os cursos do PRONERA possuem uma estrutura de funcionamento que se diferencia dos demais, em funcionamento na universidade, ao adotar o Regime de Alternância, Tempo-Escola e Tempo-Comunidade. Ao tratar do Regime de Alternância, Hage (2011, p. 338) assinala que se trata da: 
[...] possibilidade de organizar a escola e o ensino no campo, de modo a fortalecer a participação das famílias na escola, o diálogo entre os conhecimentos escolares e os saberes da tradição, articulação mais sólida entre educação e trabalho, e a valorização da vida e da cultura das populações do campo, na escola e na sociedade [...].

Essa organização funciona tendo, em cada disciplina, "uma atuação intensiva, presencial e outra não presencial, sob a forma de trabalho dirigido e executado na comunidade de origem das/os educandas/os. A parte intensiva se fará de forma concentrada, com 8 horas aulas por dia, perfazendo um total de $80 \%$ das horas/aula" (UFPB, 2007).

A organização por alternância foi baseada em experiências de educação, na França, apresentando-se como uma possibilidade educacional que pode coadunar com as necessidades sociais e históricas das populações do campo, combinando e alternando momentos na instituição educacional (Tempo Escola) e momentos no espaço comunitário (Tempo Comunidade), visando relacionar a realidade cotidiana e o conhecimento científico, valorizando a experiência, os saberes e a cultura do campo.

A metodologia da alternância adotada no Curso de Pedagogia possibilita espaços e tempos de estudo e aprendizagens diferenciados e o entrecruzamento de teoria e prática. A materialidade da vida no campo, trazida para a sala de aula possibilita o diálogo com o conhecimento sistematizado e a partir das reflexões se torna um concreto pensado que alimenta a práxis.

A estruturação desses cursos, por ocorrerem em ritmo diferenciado dos demais da instituição forçam-na a buscar flexibilizar os trâmites e calendários letivos rígidos. Eles também trazem a presença dos camponeses e movimentos sociais para dentro da universidade, provocando essa instituição historicamente elitista a romper as cercas que a separam das classes trabalhadoras e trazem a marca dos sujeitos coletivos afirmando o direito ao conhecimento e à educação em todos os níveis.

\section{RETROCESSOS E RESISTÊNCIAS: NOVOS ESPAÇOS DE APRENDIZAGENS}

Diante do atual contexto de negação de direitos educacionais que limita a criticidade própria da educação, é importante retomar a construção da Educação do Campo para fazer frente a ideologias neoliberais na educação e às diversas frentes de 
homogeneização e despolitização nas escolas e à defesa da construção de um currículo que atenda às especificidades a partir dos diferentes contextos em que estão inseridas nossas escolas.

A luta do Movimento da Educação do Campo é por uma escola popular e democrática, que se constituiria de dois modos complementares e interligados: por um lado, criando estruturas e processos democráticos que orientariam a vida escolar, valorizando o exercício de experiências democráticas em seu interior; e, por outro, construindo um currículo que considere seriamente os saberes, culturas e problemas reais dos sujeitos que a constituem.

Partindo do sentido amplo de educação como prática social, como processo em que se realiza a socialização da cultura e dos conhecimentos produzidos pelo homem e da escola como o espaço privilegiado de apropriação e produção de saber, sendo este espaço (institucionalizado) orientado por concepções e normas existentes em função do alcance dos objetivos de formação, vemos a existência de diferentes níveis de decisão e de organização da educação em instâncias macro e micro (sociais e políticas), envolvendo também diferentes atores sociais.

Cabe, então, avaliarmos as relações entre uma esfera e outra em que, por um lado temos a produção e a inserção de orientações e regras que visam a influenciar ou conduzir a ação dos atores sociais (as políticas educacionais e de gestão, os marcos regulatórios, as diretrizes organizacionais e curriculares etc.); de outro lado, temos esses atores e as formas como se apropriam e transformam essas mesmas orientações e regras. Trata-se, por isso mesmo, de um fenômeno complexo, pois estão em disputa interesses, ideias, valores e intencionalidades diferentes (muitas vezes antagônicos) em relação à educação.

Em todo caso, no contexto brasileiro, estas orientações ou regras mais gerais que visam a influenciar a ação dos atores sociais no contexto da escola e os seus resultados - as políticas educacionais (de gestão, de organização e de financiamento) são marcadas pela lógica da descontinuidade (ausência de planejamentos de longo prazo) e pela centralização das decisões, desfavorecendo a articulação com os sistemas de ensino e o Governo Federal, o que, segundo Dourado (2007, p. 926), “evidencia limites estruturais à lógica políticopedagógica dos processos de proposição e materialização das políticas educacionais”. Isto implicaria em pequenas mudanças ou adequações no cotidiano escolar, mas não em possibilidades de mudanças significativas nos sistemas de ensino. 
O autor destaca a necessidade do desenvolvimento de uma estrutura organizacional apropriada, que favoreça a construção de uma cultura aberta à mudança como condições necessárias para que a escola possa se transformar continuamente.

Construir espaços democráticos tem sido um grande desafio nas escolas e precisa ser alcançado passo a passo desenvolvendo situações de participação coletiva em todas as suas atividades; com isso contribuirá decisivamente para ampliar os espaços de resistência e criará condições para significativas transformações que poderão assegurar melhores condições de vida ao conjunto da população.

É importante destacar, como o faz Bordenave (1989, p. 16), que “[...] a participação não é somente um instrumento para a solução de problemas, mas, sobretudo, uma necessidade fundamental do ser humano". Nesse sentido, é de importância vital valorizar a reflexão coletiva, desencadeando momentos onde se dará um processo favorável ao amadurecimento do nosso compromisso, enquanto educadoras e educadores populares. Esse processo contribui para nos tornarmos críticos de nossa própria realidade, possibilitarnos-á, enfim, alcançar um nível de consciência que nos conduza à busca de uma constante reconstrução de nosso fazer pedagógico.

No entendimento, portanto, de que toda ação humana intencional, tomada na relação dos homens entre si, que envolve relações de poder, seja consciente ou não, representa ações políticas e, entendendo também que nossas ações e omissões frente ao poder político institucionalizado refletirão sobre a vida de todos, é que concebemos a educação como um ato político.

Nessa perspectiva, Paulo Freire nos faz refletir sobre o sentido político da educação quando afirma que a negação da educação como ato político pode significar, por um lado a ingenuidade de quem acredita que seus atos são meramente neutros e indiferentes à realidade na qual atua; e pode, também, significar uma ação intencional de quem reconhece o poder da educação sobre a vida das pessoas.

Nessa direção, a neutralidade entendida por Freire (1997) não é possível na educação. Não se pode fazer educação afastada de uma intencionalidade que vincula utopias, desejos, objetivos, mesmo que estes estejam no inconsciente. A neutralidade na educação não é a livre atitude de quem não quer se posicionar politicamente sobre dada situação. Em suas próprias palavras ele nos indaga e instiga:

Que é mesmo a minha neutralidade senão a maneira cômoda, talvez, mas hipócrita, de esconder a minha opção ou meu medo de acusar a injustiça? 'Lavar as mãos' em face da opressão é reforçar o poder do opressor, é 
optar por ele. Como posso ser neutro diante da situação, não importa qual seja ela, em que o corpo das mulheres e dos homens vira puro objeto de espoliação e descaso? (FREIRE, 1997, p. 126).

É, portanto, com a perspectiva de desvendar os mecanismos ideológicos que nos induzem a pensar que educação e política são dois processos que não se intercruzam, no sentido de contribuir para que homens e mulheres saiam do estado de inconsciência das ações que os prendem à situação de eternos dominados, que Adriano Nogueira em diálogo com Paulo Freire nos impele a pensar a educação na concepção da educação popular, a qual é entendida como um processo de capacitação, organização e mobilização (FREIRE; NOGUEIRA, 1993).

Entendendo que a educação é sempre um ato político, podemos dizer que a educação mediada pelo processo de ensino-aprendizagem na produção de conhecimento possibilita a humanização. E nesta lógica os movimentos sociais populares vêm contribuindo em nossa conscientização, mobilização e na transformação, portanto, defendem uma perspectiva progressista e emancipatória de educação e de sociedade, em que se visualiza a necessidade da construção da cultura da participação democrática no interior das instituições de ensino pela via do desenvolvimento da autonomia de educadores, estudantes e comunidades.

\section{CONSIDERAÇÕES}

Refletir sobre as políticas públicas que se estabeleceram no Brasil para a educação do campo foi um dos objetos de estudo deste texto. Após uma apresentação dos princípios balizadores das ações dos movimentos sociais populares do campo e das políticas públicas para a educação nos últimos 20 anos, verificamos que os documentos analisados e os autores estudados corroboraram com o argumento que a partir da ascensão do governo com viés político de esquerda houve uma atuação direta dos movimentos sociais no "contexto de influência" e na "produção de textos" (BOWE; BALL; GOLD, 1992), que direcionaram programas e projetos que priorizaram as minorias e a diversidade existente no Brasil.

Observou-se que os movimentos sociais campesinos contribuíram para a instituição do debate sobre a escola campesina e através de práticas pedagógicas contextualizadas foram exemplos de respeito à diferença e à promoção da inclusão da população escolar do campo. 
Os avanços encontrados foram na instituição de diretrizes para a educação escolar do campo e os programas que foram criados e implementados a partir da criação da SECADI, oportunizando que a parcela da população que reside no espaço campesino fosse contemplada com cursos de formação básica, profissional e de graduação, projetos de formação inicial e continuada para professores, livros didáticos, construções de escolas, infraestrutura e transporte que possibilitaram um atendimento humano, que favoreceu uma educação de qualidade para todos.

Como retrocessos registra-se que após o afastamento de Dilma Rousseff da presidência da República, período compreendido entre 2016 e 2018, estabelece-se um período de latência que propiciou a nova estrutura da educação no Brasil, efetivada através do Decreto n ${ }^{\circ}$ 9.665, de 02 de janeiro de 2019, que excluiu a Secretaria da Educação do Campo da estrutura governamental, denotando a necessidade de novos estudos para verificação das consequências dessa ação.

Através deste trabalho apresentamos as reflexões resultantes das análises que indicaram a construção de ações em prol da educação do campo na agenda governamental no período de 1998 a 2016, com conquistas legais significativas resultantes de embates entre os movimentos sociais e o governo federal, que apresentou, no período, aspectos que podemos considerar como democráticos participativos.

\section{REFERÊNCIAS}

ARROYO, Miguel Gonzalez. A educação básica e o movimento social do campo. In: ARROYO, Miguel Gonzalez; CALDART, Roseli Salete; MOLINA, Mônica Castagna. Por uma educação do campo. Petrópolis: Vozes, 2004. p. 10-27.

Prefácio. In: KOLLING, Edgar Jorge; NERY, Ir.; MOLINA, M. C. A Educação Básica e o Movimento social do Campo. Brasília: Editora Universidade de Brasília, 1999. p. 9-12.

O direito a tempos-espaços de junto e digno viver. In: MOLL, Jaqueline (org.). Caminhos da educação integral no Brasil: direito a outros tempos e espaços educativos. Porto Alegre: Penso, 2012. p. 33-45.

AZEVEDO, Márcio Adriano de. Política de Educação do Campo: concepções, processos e desafios. In: NETO, Antônio Cabral et al. Pontos e contrapontos da política educacional: uma leitura contextualizada de iniciativas governamentais. Brasília: Líber Livro Editora, 2007. p. 145-173.

BALL, Stephen. Education Reform: a critical and post-structural approach. Buckingham: Open University Press, 1994. 
BARRETO, Elma S. de Sá. Políticas Públicas e Educação das Populações Rurais. In: MADEIRA, Felícia Reicher; MELO, Guiomar Nano de. Educação na América Latina: os modelos teóricos e a realidade social. SP: Cortez, 1985. p. 115-149.

BOWE, R.; BALL, S.; GOLD, A. Reforming education \& changing schools: case studies in policy sociology. London: Routledge, 1992.

BORDENAVE, Juan E. Díaz. O que é participação. 6. ed. São Paulo: Brasiliense, 1989.

BRASIL. Decreto N 7.352 , de 4 de novembro de 2010 - Dispõe sobre a política de educação do campo e o Programa Nacional de Educação na Reforma Agrária PRONERA. Diário Oficial da União, Brasília, DF, 05 nov. 2010a. Seção 1, p. 1.

Diretrizes Operacionais para a Educação Básica nas Escolas do Campo. Resolução nº 01, de 03 de abril de 2002. Brasília: MEC, 2002.

Ipea. II Pnera: relatório da II Pesquisa Nacional sobre a Educação na Reforma Agrária. Brasília, 2015. Disponível em: <http://www.ipea.gov.br/portal/images/stories/PDFs/relatoriopesquisa/150618_relatorio_ii _pesquisa\%20nacional.pdf>. Acesso em: 15 mar. 2019.

MDA/INCRA/PRONERA. Manual de Operações. Ed. rev. e atual. Brasília: MDA/INCRA/PRONERA, 2004a.

Ministério da Educação. Conselho Nacional de Educação. Parecer CNE/CEB

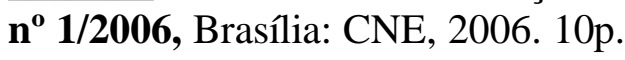

Ministério da Educação. Conselho Nacional de Educação. Parecer CNE/CEB n' 23/2007, Brasília: CNE, 2007, 12p.

Ministério da Educação. Conselho Nacional de Educação. Resolução CNE/CEB n02/2008, Brasília: CNE, 2008, 3p.

Ministério da Educação. Conselho Nacional de Educação. Resolução CNE/CEB n'05/2009, Brasília: CNE, 2009, 5p.

Ministério da Educação e Desporto. Lei de Diretrizes e Bases da Educação Nacional. No 9.394/96. Brasília: MEC, 1996.

Ministério da Educação. Portaria $\mathrm{N}^{\circ} 86$, de $1^{\circ}$ de fevereiro de 2013. Institui o Programa Nacional de Educação do Campo-PRONACAMPO. Diário Oficial da União, Brasília, DF, 04 fev. 2013. Seção 1, p. 28. Disponível em: <http://pronacampo.mec.gov.br/10-destaque/2-o-pronacampo>. Acesso em: 20 mar. 2019.

Ministério da Educação. Grupo Permanente de Trabalho de Educação do Campo. Referências para uma política nacional de educação do campo - GPTEC: Caderno de Subsídios. Coordenação de RAMOS, Marise Nogueira; MOREIRA, Telma Maria; 
SANTOS, Clarice Aparecida dos (coord.). Brasília: Secretaria de Educação Média e Tecnológica, 2004b.

Resolução $\mathbf{n}^{\mathbf{0}}$ 4, de 13 de julho de 2010, que estabeleceu as Diretrizes Curriculares Nacionais Gerais para a Educação Básica. Brasília: Ministério da Educação, 2010b.

CALADO, Alder Júlio F. Movimentos Sociais por uma Sociabilidade Alternativa. In: JEZINE, Edineide; ALMEIDA, Maria de Lourdes. Pinto de (org.). Educação e Movimentos Sociais: novos olhares. Campinas, SP: Alínea, 2007. p. 93-121.

CALDART, Roseli Salete. A Escola do Campo em Movimento. Currículo sem Fronteiras, v. 3, n. 1, p. 60-81, jan./jun. 2003. Disponível em: <bibliotecadigital.conevyt.org.mx/colecciones/.../escuela_del_campo.pdf>. Acesso em: 28 jul. 2010.

Educação em Movimento: formação de educadoras e educadores no MST. Petrópolis: Vozes, 1997.

Elementos para construção do Projeto Político-Pedagógico da Educação do Campo. In: MOLINA, Mônica Castagna; JESUS, Sônia M. S. Azevedo de (org.). Contribuições para a construção de um projeto de educação do campo. Brasília: Articulação Nacional "Por Uma Educação do Campo", 2004a. v. 5. p. 13-51.

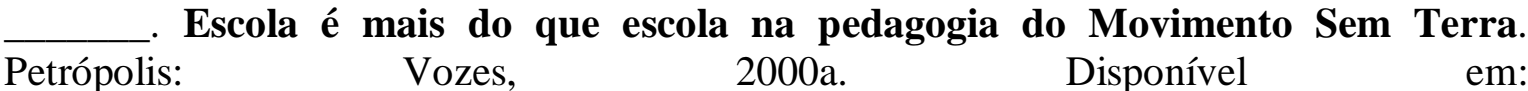
$\langle$ www.anped.org.br/reunioes/26/posteres/celiareginavendramini.rtf $\rangle$. Acesso em: 04 ago. 2010.

2004b.

Pedagogia do Movimento Sem Terra. 3. ed. São Paulo: Expressão Popular,

Pedagogia do Movimento Sem Terra: escola é mais do que escola. Petrópolis, Rio de Janeiro: Vozes, 2000b.

Sobre a educação do campo. In: SANTOS, Clarice Aparecida dos (org.). Educação do campo: campo- políticas públicas - educação. Brasília, DF: INCRA - MDA, 2008. p. 67-86.

CALDART, R. S.; ARROYO, Miguel Gonzalez; MOLINA, Mônica Castagna (org.). Por Uma Educação do Campo. Petrópolis: Vozes, 2005.

CORREA, D. M. N. Relatório Final: II Pesquisa Nacional sobre Educação na Reforma Agrária - Superintendência Regional da Paraíba. João Pessoa: Articulação Nacional "Por Uma Educação do Campo", 2013.

DOURADO, Luiz F. Políticas e gestão da educação básica no Brasil: limites e perspectivas. Revista Educação e Sociedade, Campinas, v. 28, n. 100, p. 921-946, out. 2007. 
ESMERALDO, Gema Galgani Silveira Leite; MOLINA, Mônica Castagna; ANTUNESROCHA, M. I. O Fortalecimento da Identidade Camponesa: repercussões do Programa Nacional de Educação na Reforma Agrária nos Estados do Ceará, Minas Gerais e Paraná (1998-2011). Educ. Soc. [online], v. 38, n. 140, p. 569-585, 2017.

FERNANDES, Bernardo Mançano. Os campos da pesquisa em educação do Campo: espaço e território como categorias essenciais. In: MOLINA, Mônica Castagna (org.). Educação do Campo e pesquisa: questões para reflexão. Brasília: Ministério do Desenvolvimento Agrário, 2006. p. 27-39.

Por Uma Educação Básica do Campo. In: ARROYO, Miguel. FERNANDES, B. Mançano. A Educação Básica e o Movimento Social no Campo, Brasília, 1999. p. 53 70. v. 2.

FERNANDES, Bernardo Mançano, MOLINA, Mônica C. O Campo da Educação do Campo. In: MOLINA, Mônica Castagna; JESUS, Sônia M. S. Azevedo de (org.). Contribuições para a construção de um projeto de educação do campo. Brasília, 2004. p. 53-89. v. 5.

FERNANDES, B. M.; TARLAU, Rebecca. Razões para mudar o mundo: a Educação do Campo e a contribuição PRONERA. Educ. Soc., Campinas, v. 38, n. 140, p. 545-567, jul./set. 2017. Disponível em: <http://www.scielo.br/pdf/es/v38n140/1678-4626-es-38140-00545.pdf>. Acesso em: 14 jul. 2018.

FREIRE, Paulo. Educação como prática da liberdade. Rio de Janeiro: Paz e Terra, 1983.

Educação como prática de liberdade. 25. ed. Rio de janeiro. Paz e Terra, 2002.

Pedagogia da Autonomia: saberes necessários à prática educativa. São Paulo: Paz e Terra, 1997.

Pedagogia do Oprimido. Rio de Janeiro: Paz e Terra, 1987.

FREIRE, Paulo; NOGUEIRA, Adriano. Que fazer: teoria e prática em educação popular. 4. ed. Petrópolis: Vozes, 1993.

FREITAS, Luiz Carlos de. Organização do Trabalho Pedagógico. Revista de Estudos, Novo Hamburgo, ano 14, n. 1, jul. 1991.

HAGE, Salomão Mufarrej. Por uma escola do campo de qualidade social transgredindo o paradigma (multi) seriado de ensino. Em Aberto, Brasília, v. 24, n. 85, p. 97-113, abr. 2011.

IPEA. Instituto de pesquisa econômica aplicada. Relatório da II Pesquisa Nacional de Educação em Áreas de Reforma Agrária: pesquisa qualitativa no Estado do Paraná. Rio de Janeiro, 2016. 
JESUS, Sônia M. S. Azevedo de. Questões Paradigmáticas da Construção de um Projeto Político da Educação do Campo. In: MOLINA, Mônica Castagna; JESUS, Sônia M. S. Azevedo de (org.). Contribuições para a Construção de um Projeto de Educação do Campo. Brasília, 2004. p. 109-130, v. 5.

JEZINE, E. O Pronera como Política de Acesso à Educação Superior e os Movimentos Sociais no Contexto da Globalização. In: TEODORO, A.; JEZINE, E. (org.). Movimentos Educacionais e Educação de Adultos na Ibero-América: lutas e desafios. Brasília: Liber Livro, 2011. p. 81-116.

KAUCHAKJE, Samira, Movimento Sociais no Século XXI: Matriz Pedagógica da participação sociopolítica. In: ALMEIDA, Maria de Lourdes, P.; JEZINE, Edineide (org.). Educação e Movimentos Sociais: novos olhares. Campinas, SP: Alínea, 2007. p. 75-92.

MAINAIRDES, Jefferson. Abordagem do Ciclo de Políticas: Uma contribuição para a análise de políticas Educacionais. Educ. Soc., Campinas, v. 27, n. 94, p. 47-69, jan./abr. 2007. Disponível em: <http://www.cedes.unicamp.br>. Acesso em: 18 mar. 2019.

MOLINA, Mônica Castagna; JESUS, Sônia M. S. Azevedo de (org.). Contribuições para a construção de um projeto de educação do campo. Brasília: Articulação Nacional "Por Uma Educação do Campo", 2004. v. 5.

MOLINA, Mônica Castagna. A Contribuição do Pronera na Construção de Políticas Públicas de Educação do Campo e Desenvolvimento Sustentável. 2003. Tese (Doutorado) - UnB, Brasília, 2003.

MOREIRA, Antonio Flávio Barbosa. Currículo, cultura e formação de Professores. Educar, Curitiba: Editora da UFPR, n. 17, p. 39-52. 2001.

RIBEIRO, Marlene. Movimento camponês, trabalho e educação: Liberdade, Autonomia, Emancipação: princípios/fins da formação humana. 1. ed. São Paulo: Expressão Popular, 2010.

SANTOS, B. S. A Universidade no Séc. XXI: Para uma Reforma Democrática e Emancipatória da Universidade. Educação, Sociedade \& Culturas, v. 23, p. 137-202, 2005.

Democratizar a democracia: os caminhos da democracia participativa. 2. ed. Rio de Janeiro: Civilização Brasileira, 2003.

SANTOS, C. A. Educação do Campo e Políticas Públicas no Brasil: a instituição de políticas públicas pelo protagonismo dos movimentos sociais do campo na luta pelo direito à educação. 2009. Dissertação (Mestrado) - UnB, Brasília, 2009.

SANTOS, Ramofly Bicalho dos; SILVA, Marizete Andrade da. Políticas públicas em educação do campo: Pronera, Procampo e Pronacampo. Revista Eletrônica de Educação, v. 10, n. 2, p. 135-144, 2016. 
II CONFERÊNCIA NACIONAL POR UMA EDUCAÇÃO DO CAMPO. Por Uma Política Pública de Educação do Campo. Declaração final. Luziânia -GO, 02 a 06 de agosto de 2004. Disponível em: <http://www.cnbb.org.br/documento_geral/>. Acesso em: 01 set. 2009.

SOUZA, Maria Antônia de. Educação do campo: propostas e práticas pedagógicas do MST. Petrópolis, RJ: Vozes, 2006.

UFPB. Conselho Superior de Ensino, Pesquisa e Extensão (CONSEPE). Resolução no 41/2003. Aprova o Projeto Político-Pedagógico do Curso de Graduação em Ciências Agrárias - Licenciatura à Distância, do Centro de Ciências Humanas, Sociais e Agrárias, Campus III de Bananeiras. João Pessoa, PB, 27 set. 2003.

Conselho Superior de Ensino, Pesquisa e Extensão (CONSEPE). Resolução no 17/2004. Aprova o Projeto Político-Pedagógico do Curso de História-Licenciatura, do Centro de Ciências Humanas, Letras e Artes, para educadores dos movimentos sociais do campo, vinculados aos Assentamentos da Reforma Agrária do INCRA, no Brasil. Campus I. João Pessoa/PB, 07 jun. 2004.

UFPB. Conselho Superior de Ensino, Pesquisa e Extensão. Resolução N. 61/2007 -

Aprova o Projeto Político-Pedagógico do Curso de Pedagogia - Licenciatura, do Centro de Educação, Campus I, desta Universidade, para educadores dos movimentos sociais do campo vinculados aos Assentamentos da Reforma Agrária do INCRA, no Brasil, Campus I. João Pessoa, PB, 12 dez. 2007.

Recebido: 05/03/2019

Aceito: 30/03/2019 